7

\title{
Determination of kinetic parameters for biomass combustion
}

Álvarez $A^{a}$, Pizarro $C^{a, *}$, García $R^{b}$, Bueno J.L. ${ }^{a}, G$. Lavín $A^{a}$

${ }^{a}$ Department of Chemical and Environmental Engineering. Faculty of Chemistry

University of Oviedo, Julián Clavería 8, 33006, Oviedo, Asturias, Spain.

b Instituto Nacional del Carbón, INCAR-CSIC, c/ Francisco Pintado Fe 26, 33011. Oviedo, Spain

\section{ABSTRACT}

The aim of this work is to provide a wide database of kinetic data for the most common biomass by thermogravimetric analysis (TGA) and differential thermogravimetry (DTG). Due to the characteristic parameters of DTG curves, a two-stage reaction model is proposed and the kinetic parameters obtained from model-based methods with energy activation values for first and second stages in the range $1.75 \cdot 10^{4}-1.55 \cdot 10^{5} \mathrm{~J} / \mathrm{mol}$ and $1.62 \cdot 10^{4}-2.37 \cdot 10^{5} \mathrm{~J} / \mathrm{mol}$, respectively. However, it has been found that Flynn-Wall-Ozawa and KissingerAkahira-Sunose model-free methods are not suitable to determine the kinetic parameters of biomass combustion since the assumptions of these two methods were not accomplished in the full range of the combustion process.

\section{Keywords}

Biomass, combustion, kinetic parameters, Coats-Redfern method, thermogravimetric analysis

\section{INTRODUCTION}


The importance of waste biomass as an energy source is likely to increase during the coming years as a result of European energy policy targets (European Environment Agency (EEA), 2010). The total amount of potential biomass in Spain is about 88,677,193 t/year (data from Spanish Renewable Energies Plan 2011-2020 referencing in (Álvarez et al., 2015)), belonging to the agricultural and harvesting residues the largest quantity (up to $37.8 \%$ of the total potential biomass).

There are still some problems in current biomass combustion furnaces, such as low thermal efficiency, instability of heat load, and slagging (Szemmelveisz et al., 2009; Yang et al., 2004). Computational Fluid Dynamics (CFD) could be useful in solving these problems (Dixon et al., 2005; Ma et al., 2007), but it is absolutely essential having a deep knowledge of the composition (proximate, ultimate and structural analysis) and thermal behaviour as well as the kinetics of the combustion process of biomass.

The aim of this article is to determine the combustion kinetics parameters of the most commonly used types of biomass in Spain using a thermogravimetric analyser (TGA), since this technique is widely used in the analysis of weight loss characteristics of biomass fuels (Garcia-Maraver et al., 2015; Kok and Özgür, 2013; Maia and de Morais, 2016)

\section{MATERIALS AND METHODS}

\subsection{Materials}

Twenty eight different biomass samples were tested to obtain their activation energy, $E_{a}$, and pre-exponential Arrhenius factor, $k_{0}$, values for combustion. 
These samples were selected trying to track a wide variety of different biomass origins such as commercial fuels, industrial and forest wastes, energy crops and cereals. Their proximate and ultimate analysis data and other properties are available in a database previously published by this research group (García et al., 2014a, 2014b) . These samples were pre-treated to assure homogeneity and reproducibility of the carried-out tests and to that aim they were air-dried for a day at room temperature, grinded and sieved to $250-500 \mu \mathrm{m}$.

\subsection{TG method}

$10 \mathrm{mg}$ of the sample were subjected to thermal decomposition at 4 different low heating rates $(5,10,15$ and $20 \mathrm{~K} / \mathrm{min})$ in a Perkin-Elmer STA 6000 , using $40 \mathrm{ml} / \mathrm{min}$ of both purge $\left(\mathrm{N}_{2}\right)$ and carrier (air) gas.

Particle diameter and, consequently, heating rates must be low, particle size should be smaller than 500 $\mu$ m (Garcia-Maraver et al., 2015; Parthasarathy et al., 2013; Shen et al., 2009), while oxidizing gas flux high in order to guarantee chemical-kinetic reaction control, avoiding as possible temperature and concentration gradients (Parthasarathy et al., 2013).

\subsection{Kinetic models}

In the case of combustion some authors consider just one global reaction divided in three different stages (drying, pyrolysis and char combustion) (Fang et al., 2013; Gangavati et al., 2005), others consider two parallel reactions with three reaction stages (Wang et al., 2014). Finally (Gil et al., 2010) considers a two stage reaction, with a first step between $200-365^{\circ} \mathrm{C}$ (oxidative degradation) 
73 followed by combustion of char between $365-500^{\circ} \mathrm{C}$. A similar model is

74 proposed by (Shen et al., 2009) and (Fang et al., 2006), who apply those

75 methods to a two reaction oxidation-reduction pyrolysis.

76 There are two main mathematical approaches to obtain the descriptors of 77 combustion kinetics of biomass samples: (a) model-free methods (iso78 conversional methods) and (b) model-based methods. Both approaches depart 79 from a general conversion-time relationship:

$$
\frac{\mathrm{d} \alpha}{\mathrm{dt}}=\mathrm{k}(\mathrm{T}) \cdot \mathrm{f}(\alpha)
$$

80 Where $f(\alpha)$ is the mechanistic temr and $k(T)$ the thermal dependence term

81 that can be defined by Arrhenius law:

$$
\mathrm{k}(\mathrm{T})=\mathrm{k}_{0} \cdot \mathrm{e}^{-\mathrm{E}_{\mathrm{a}} / \mathrm{RT}}
$$

82 Conversion rate can be defined as a relation between initial ( $\left.\mathrm{m}_{0}\right)$, final

$83\left(\mathrm{~m}_{\infty}\right)$ and instantaneous $\left(\mathrm{m}_{\mathrm{t}}\right)$ sample mass. These data can be obtained from 84 each sample TG profile.

$$
\alpha=\frac{m_{0}-m_{t}}{m_{0}-m_{\infty}}
$$

85 The kinetic term $f(\alpha)$ depends on the conditions and the stage of the reaction 86 to study, but it can be usually expressed as (1-a) (Bahng et al., 2009; Fang et 87 al., 2006; Shen et al., 2009), if first reaction order is considered. If other reaction 88 model is required it should be substituted by one of the expressions shown at 89 Table 1. Combining both expressions, the experimental rate of reaction may be 90 formulate as:

$$
\frac{\mathrm{d} \alpha}{\mathrm{dt}}=\mathrm{k}_{0} \cdot \mathrm{e}^{-\mathrm{E}_{\mathrm{a}} / \mathrm{RT} \cdot \mathrm{f}(\alpha)}
$$


If the heating rate $\beta=\mathrm{dT} / \mathrm{dt}$, is included in the previous differential equation, a new expression is obtained following a simple mathematical procedure which can be seen in previous articles such as (Gil et al., 2010; Maia and de Morais, 2016):

$$
\frac{\mathrm{d} \alpha}{\mathrm{dT}}=\frac{1}{\beta} \cdot \mathrm{k}_{0} \cdot \mathrm{e}^{-\mathrm{E}_{\mathrm{a}} / \mathrm{RT} \cdot \mathrm{f}(\alpha)}
$$

95 Therefore:

$$
\frac{\mathrm{d} \alpha}{\mathrm{f}(\alpha)}=\frac{\mathrm{k}}{\beta} \cdot \mathrm{dT} \rightarrow \frac{\mathrm{d} \alpha}{\mathrm{f}(\alpha)}=\frac{k_{0}}{\beta} \cdot \mathrm{e}^{-\mathrm{E}_{\mathrm{a}} / \mathrm{RT} \mathrm{dT}}
$$

Then the following integer, that must be numerically solved, is obtained:

$$
\mathrm{g}(\alpha)=\int_{0}^{\alpha} \frac{\mathrm{d} \alpha}{\mathrm{f}(\alpha)}=\frac{\mathrm{k}_{0}}{\beta} \int_{\mathrm{T}_{0}}^{\mathrm{T}} \mathrm{e}^{-\mathrm{E}_{\mathrm{a}} / \mathrm{RT} \mathrm{dT}}=\frac{\mathrm{k}_{0} E_{a}}{\beta R} P\left(\frac{E_{a}}{R T}\right)
$$

The function $P\left(E_{a} / R T\right)$ has no exact solution. Thus Eq. (7) can be solved by numerical methods or approximations as can be seen in (White et al., 2011).

2.3.1. Model-free methods

The model-free methods allow for evaluating the Arrhenius parameters without choosing the reaction order (Janković et al., 2009; Ravi et al., 2012). These methods rest upon the isoconversional principle, which states that, at a constant extent of conversion, the reaction rate is a function only of the temperature (Vyazovkin and Sbirrazzuoli, 2006).

\subsubsection{Flynn-Wall-Ozawa method}

The solution of Eq. 7 using Doyle's approximation (Eq. 8) (Doyle, 1961), is the Flynn-Wall-Ozawa (FWO) method (Eq. 9) (Flynn and Wall, 1966; Ozawa, 1965). 


$$
\ln \left[p\left(\frac{E_{a}}{R T}\right)\right] \simeq-5.331-1.052 \frac{E_{a}}{R T}
$$

109

$$
\ln (\beta)=\ln \left(\frac{\mathrm{k}_{0} E_{a}}{R g(\alpha)}\right)-5.331-1.052 \frac{E_{a}}{R T}
$$

111 measurements with different heating rates at the fixed conversion value $\alpha=\alpha_{i}$,

112 the plot of $\ln (\beta)$ vs. $T^{-1}$ is a straight line with the slope $m=-1.052 E_{a} / R$.

113 2.3.1.2. Kissinger-Akahira-Sunose method

114 The Kissinger-Akahira-Sunose method (KAS) is obtained using Eq. 10,

115 which is valid for $20 \leq E_{a} / R T \leq 50$ (Sbirrazzuoli et al., 2009).

$$
p\left(\frac{E_{a}}{R T}\right) \simeq \frac{e^{-E_{a} / R T}}{\left(\frac{E_{a}}{R T}\right)^{2}}
$$

In KAS method, the relation between the temperature and heating rate is

117 given by Eq. 11 (Kissinger, 1957).

$$
\ln \left(\frac{\beta}{\mathrm{T}^{2}}\right)=\ln \left(\frac{\mathrm{k}_{0} \mathrm{R}}{\mathrm{E}_{\mathrm{a}} \mathrm{g}(\alpha)}\right)-\frac{\mathrm{E}_{\mathrm{a}}}{\mathrm{RT}}
$$

118 The plot of the left side of Eq. 11 vs. $\mathrm{T}^{-1}$ at constant conversion value is a 119 straight line with the slope $m=-E_{a} / R$.

120 2.3.2. Model-based methods. Coats-Redfern method.

121 Coats-Redfern method uses the asymptotic series expansion for approximating the exponential integral in Eq. 7 (Coats and Redfern, 1964).

$$
\ln \left(\frac{g(\alpha)}{T^{2}}\right)=\ln \left(\frac{k_{0} R}{\beta E_{a}}\left(1-\frac{2 R \bar{T}}{E_{a}}\right)\right)-\frac{E_{a}}{R T}
$$


If term $2 \mathrm{RT} / \mathrm{E}_{\mathrm{a}}$ is much lower than one it can be ignored, being the right logarithmic term constant:

$$
\ln \left(\frac{g(\alpha)}{T^{2}}\right)=\ln \left(\frac{k_{0} R}{\beta E_{a}}\right)-\frac{E_{a}}{R T}
$$

Plotting the left side of Eq. 13 vs. $\mathrm{T}^{-1}, \mathrm{E}_{\mathrm{a}}$ and $\mathrm{k}_{0}$ are obtained from the slope and intercept respectively. Finally, the model that gives the best linear fit is selected as the chosen model.

Several reaction model for $g(\alpha)$ and $f(\alpha)$ are listed at Table 1 . With these mathematical approach the kinetic triplet (decomposition model/reaction order, pre-exponential Arrhenius factor and activation energy) can be obtained from thermal decomposition data in a thermobalance scale (Bahng et al., 2009).

\section{RESULTS AND DISCUSSION}

\subsection{Parameters of DTG curves}

The characteristic parameters of DTG plots, which are presented in Fig. 1, are shown in Table 2. As shown in Table 2, the combustion behaviour of biomass samples studied is almost the same. There are two steps in combustion of biomass, except for charcoal, lignin and cellulose which presented only one step. The first step is related with combustion of cellulose and hemicelluloses and the second one is related with the lignin fraction. All the temperatures at maximum DTG ( $T_{\text {peak }}$ ) of first stage are in the range between 249-353 ${ }^{\circ} \mathrm{C}$, while the range for second stage is $414-627^{\circ} \mathrm{C}$. Temperature at maximum weight loss rate of cellulose is $338^{\circ} \mathrm{C}$, which correspond to the first stage while in the case of lignin this temperature is $548^{\circ} \mathrm{C}$ belonging to second 
stage. Thus, the first step is related with combustion of cellulose and hemicelluloses and the second one is related with the lignin fraction.

Due to the data in Table 2, a two-stage reaction kinetic scheme has been proposed in this article:

$$
\begin{aligned}
& \text { A (solid) } \rightarrow \text { A' (solid) + B1 (gas) (stage 1) }
\end{aligned}
$$

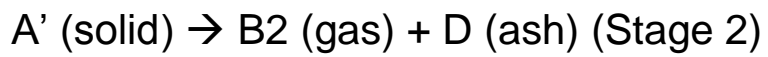

\subsection{Kinetic parameters}

The samples of biomass fuels were subjected to four heating ramps at 5,10 , 15 and $20 \mathrm{~K} / \mathrm{min}$. Obtained data was adjusted using previously described FWO, KAS and Coats-Redfern method as well as numerically using Scientist software, supposing first reaction order in all cases, which showed a really good mathematical adjust. In that way, a four point straight line was obtained for each conversion value from 10 to $90 \%$, so a value of $E_{a}$ is obtained for each conversion (FWO and KAS methods) while only one heating ramp data (15 $\mathrm{K} / \mathrm{min}$ ) were necessary when Coats-Redfern or numerical methods were used to obtain the kinetic triplet. The obtained kinetic data are shown at Table 3 and Table 4 for Coats-Redfern and numerical solutions respectively.

When FWO or KAS method were applied, their particular assumptions were only accomplished in the a range of conversion belonging to hemicelluloses and cellulose fractions, while at the level of conversion for which the combustion of lignin starts the assumptions were not accomplished (Fig 2). In Fig 2 the values of $\mathrm{E}_{\mathrm{a}} / \mathrm{RT}$ for $\mathrm{FWO}$ and KAS methods are plotted against temperature as well as dotted lines for maximum and minimum $E_{a} / R T$ values for both methods. It can 
be seen clearly that the assumptions of FWO and KAS methods were only accomplished in the first stage with $E_{a} / R T$ values (red and green lines) between dotted lines while these coloured lines are below minimum dotted line when the second stage takes place. In commercial lignin and charcoal samples, the assumptions were not accomplished at all. Taking into account that charcoal is mainly composed of lignin, it is clear that FWO and KAS methods cannot predict activation energy of biomass combustion when lignin decomposition takes place.

Regarding Coats-Redfern and numerical method kinetic data, the activation energy in both stages is almost the same although it must be stated that in most samples this value is slightly higher in second stage. However, the activation energy of lignin is lower than cellulose, this is thought to be because of the synergistic effect. Since both stages are overlapped, in the Coats-Redfern method a $\gamma$-factor is used in order to link both stages:

$$
\frac{\mathrm{d} \alpha}{\mathrm{dT}}=\gamma\left(\frac{\mathrm{d} \alpha}{\mathrm{dT}}\right)_{\text {stage } 1}+(1-\gamma)\left(\frac{\mathrm{d} \alpha}{\mathrm{dT}}\right)_{\text {stage } 2}
$$

The $\gamma$-factor is modelled as a modified Gomperzt function (Collado et al., 2016):

$$
\gamma=1-A \exp \left\{-\exp \left(\frac{\mu e}{A}\left(T_{c}-T\right)+1\right)\right\}
$$

Figures $3 a$ and $3 b$ show the simulations of the Coats-Redfern method. As it can be seen in Table 5, where the Gomperzt parameters are shown, A values are close to 1 and $T_{c}$ is the turning point between both stages, while $\mu$ values are related with the rate of change of the $\gamma$-factor. 


\section{CONCLUSIONS}

There were determined the kinetic parameters (activation energy and the pre-exponential factor of Arrhenius expression) for 28 biomass samples by

Coats-Redfern method. All of them showed good adjust to first global reaction order. It was experimentally demonstrated that FWO and KAS method are not suitable for getting the kinetic parameters of the combustion of biomass.

\section{ACKNOWLEDGEMENTS}

This article is greatly indebted to MINECO for the economic support given to the Normalized vegetable Biomass for Eficient Energetic Trigeneration project (MINECO-13-CTQ2013-45155-R) and Consejería de Economía y Empleo del

Principado de Asturias for the economic support given to the TRIBIONOR project (PCTI Asturias 2013-2017, Ref. FC-15-GRUPIN14-095), which makes the continuation of research in this field possible.

A. Álvarez acknowledges receipt of a graduate fellowship from the Severo Ochoa Program (Principado de Asturias, Spain). We also wish to thank many companies such as Pellets Asturias, Factor Verde, Molygrasa, Dibiosur, Enfosur, Acciona, Nutral, Arrocerías Dorado, most of the necessary biomass samples. 


\section{REFERENCES}

1. Álvarez, A., Pizarro, C., García, R., Bueno, J.L., 2015. Spanish biofuels heating value estimation based on structural analysis. Ind. Crops Prod. 77, 983-991. doi:10.1016/j.indcrop.2015.09.078

2. Bahng, M.-K., Mukarakate, C., Robichaud, D.J., Nimlos, M.R., 2009. Current technologies for analysis of biomass thermochemical processing: A review. Anal. Chim. Acta 651, 117-138. doi:10.1016/j.aca.2009.08.016

3. Coats, A.W., Redfern, J.P., 1964. Kinetic Parameters from Thermogravimetric Data. Nature 201, 68-69. doi:10.1038/201068a0

4. Collado, S., Rosas, I., González, C., Diaz, M., 2016. Biodegradation of phydroxybenzoic acid by Pseudomonas putida. Desalination Water Treat. 57, 15230-15240. doi:10.1080/19443994.2015.1072584

5. Dixon, T.F., Mann, A.P., Plaza, F., Gilfillan, W.N., 2005. Development of advanced technology for biomass combustion-CFD as an essential tool. Fuel, Special Issue Dedicated to Professor Terry Wall 84, 13031311. doi:10.1016/j.fuel.2004.09.024

6. Doyle, C.D., 1961. Kinetic analysis of thermogravimetric data. J. Appl. Polym. Sci. 5, 285-292. doi:10.1002/app.1961.070051506

7. European Environment Agency (EEA), 2010. Europe 2020: A strategy for smart, sustainable and inclusive growth [WWW Document]. URL http://www.eea.europa.eu/policy-documents/com-2010-2020-europe2020 (accessed 2.11.15).

8. Fang, M.X., Shen, D.K., Li, Y.X., Yu, C.J., Luo, Z.Y., Cen, K.F., 2006. Kinetic study on pyrolysis and combustion of wood under different oxygen concentrations by using TG-FTIR analysis. J. Anal. Appl. Pyrolysis 77, 22-27. doi:10.1016/j.jaap.2005.12.010

9. Fang, X., Jia, L., Yin, L., 2013. A weighted average global process model based on two-stage kinetic scheme for biomass combustion. Biomass Bioenergy 48, 43-50. doi:10.1016/j.biombioe.2012.11.011

10. Flynn, J.H., Wall, L.A., 1966. General treatment of the thermogravimetry of polymers. J. Res. Natl. Bur. Stand. Sect. Phys. Chem. 70A, 487. doi:10.6028/jres.070A.043

11. Gangavati, P.B., Safi, M.J., Singh, A., Prasad, B., Mishra, I.M., 2005. Pyrolysis and thermal oxidation kinetics of sugar mill press mud. Thermochim. Acta 428, 63-70. doi:10.1016/j.tca.2004.09.026

12. García, R., Pizarro, C., Lavín, A.G., Bueno, J.L., 2014a. Spanish biofuels heating value estimation. Part I: Ultimate analysis data. Fuel 117, Part B, 1130-1138. doi:10.1016/j.fuel.2013.08.048

13. García, R., Pizarro, C., Lavín, A.G., Bueno, J.L., 2014b. Spanish biofuels heating value estimation. Part II: Proximate analysis data. Fuel 117, Part B, 1139-1147. doi:10.1016/j.fuel.2013.08.049

14. Garcia-Maraver, A., Perez-Jimenez, J.A., Serrano-Bernardo, F., Zamorano, M., 2015. Determination and comparison of combustion kinetics parameters of agricultural biomass from olive trees. Renew. Energy 83, 897-904. doi:10.1016/j.renene.2015.05.049 
15. Gil, M.V., Casal, D., Pevida, C., Pis, J.J., Rubiera, F., 2010. Thermal behaviour and kinetics of coal/biomass blends during co-combustion. Bioresour. Technol. 101, 5601-5608. doi:10.1016/j.biortech.2010.02.008

16. Janković, B., Kolar-Anić, L., Smičiklas, I., Dimović, S., Aranđelović, D., 2009. The non-isothermal thermogravimetric tests of animal bones combustion. Part. I. Kinetic analysis. Thermochim. Acta 495, 129-138. doi:10.1016/j.tca.2009.06.016

17. Kissinger, H.E., 1957. Reaction Kinetics in Differential Thermal Analysis. Anal. Chem. 29, 1702-1706. doi:10.1021/ac60131a045

18. Kok, M.V., Özgür, E., 2013. Thermal analysis and kinetics of biomass samples. Fuel Process. Technol. 106, 739-743. doi:10.1016/j.fuproc.2012.10.010

19. Ma, L., Jones, J.M., Pourkashanian, M., Williams, A., 2007. Modelling the combustion of pulverized biomass in an industrial combustion test furnace. Fuel 86, 1959-1965. doi:10.1016/j.fuel.2006.12.019

20. Maia, A.A.D., de Morais, L.C., 2016. Kinetic parameters of red pepper waste as biomass to solid biofuel. Bioresour. Technol. 204, 157-163. doi:10.1016/j.biortech.2015.12.055

21. Ozawa, T., 1965. A New Method of Analyzing Thermogravimetric Data. Bull. Chem. Soc. Jpn. 38, 1881-1886. doi:10.1246/bcsj.38.1881

22. Parthasarathy, P., Narayanan, K.S., Arockiam, L., 2013. Study on kinetic parameters of different biomass samples using thermo-gravimetric analysis. Biomass Bioenergy 58, 58-66. doi:10.1016/j.biombioe.2013.08.004

23. Ravi, P., Vargeese, A.A., Tewari, S.P., 2012. Isoconversional kinetic analysis of decomposition of nitropyrazoles. Thermochim. Acta 550, 83-89. doi:10.1016/j.tca.2012.10.003

24. Sbirrazzuoli, N., Vincent, L., Mija, A., Guigo, N., 2009. Integral, differential and advanced isoconversional methods: Complex mechanisms and isothermal predicted conversion-time curves. Chemom. Intell. Lab. Syst., Chimiometrie 2007, Lyon, France, 29-30 November 2007 96, 219-226. doi:10.1016/j.chemolab.2009.02.002

25. Shen, D.K., Gu, S., Luo, K.H., Bridgwater, A.V., Fang, M.X., 2009. Kinetic study on thermal decomposition of woods in oxidative environment. Fuel 88, 1024-1030. doi:10.1016/j.fuel.2008.10.034

26. Szemmelveisz, K., Szücs, I., Palotás, Á.B., Winkler, L., Eddings, E.G., 2009. Examination of the combustion conditions of herbaceous biomass. Fuel Process. Technol. 90, 839-847. doi:10.1016/j.fuproc.2009.03.001

27. Vyazovkin, S., Sbirrazzuoli, N., 2006. Isoconversional Kinetic Analysis of Thermally Stimulated Processes in Polymers. Macromol. Rapid Commun. 27, 1515-1532. doi:10.1002/marc.200600404

28. Wang, G., Zhang, J., Shao, J., Ren, S., 2014. Characterisation and model fitting kinetic analysis of coal/biomass co-combustion. Thermochim. Acta 591, 68-74. doi:10.1016/j.tca.2014.07.019

29. White, J.E., Catallo, W.J., Legendre, B.L., 2011. Biomass pyrolysis kinetics: A comparative critical review with relevant agricultural residue case 
studies. J. Anal. Appl. Pyrolysis 91, 1-33.

doi:10.1016/j.jaap.2011.01.004

30. Yang, Y.B., Sharifi, V.N., Swithenbank, J., 2004. Effect of air flow rate and fuel moisture on the burning behaviours of biomass and simulated municipal solid wastes in packed beds. Fuel, Fundamental Mechanisms of Biomass, Pyrolysis and Oxidation 83, 1553-1562. doi:10.1016/j.fuel.2004.01.016 
314 TABLES

315 Table 1. Solid state rate equations

316 Table 2. DTG data of biomass samples

317 Table 3. Kinetic parameters obtained by means of Coats-Redfern method.

318 Table 4. Kinetic parameters obtained by numerical solution.

319 Table 5. Gompertz model parameters of the biomass samples analysed 
Table 1. Solid state rate equations

\begin{tabular}{cccc}
\hline Abbreviation & Reaction model & $\mathbf{f}(\boldsymbol{\alpha})$ & $\mathbf{g}(\boldsymbol{\alpha})$ \\
\hline P2 & Power Law & $2 \alpha^{1 / 2}$ & $\alpha^{1 / 2}$ \\
P3 & Power Law & $3 \alpha^{2 / 3}$ & $\alpha^{1 / 3}$ \\
P4 & Power Law & $4 \alpha^{3 / 4}$ & $\alpha^{1 / 4}$ \\
A2 & Avarami-Erofe'ev & $2(1-\alpha)[-\ln (1-\alpha)]^{1 / 2}$ & {$[-\ln (1-\alpha)]^{1 / 2}$} \\
A3 & Avarami-Erofe'ev & $3(1-\alpha)[-\ln (1-\alpha)]^{2 / 3}$ & {$[-\ln (1-\alpha)]^{1 / 3}$} \\
A4 & Avarami-Erofe'ev & $4(1-\alpha)[-\ln (1-\alpha)]^{3 / 4}$ & {$[-\ln (1-\alpha)]^{1 / 4}$} \\
\hline & Reaction orders and geometrical contractions \\
F1 & First order & $1-\alpha$ & $-\ln (1-\alpha)$ \\
F2 & Second order & $(1-\alpha)^{2}$ & $(1-\alpha)^{-1}-1$ \\
F3 & Third order & $(1-\alpha)^{3}$ & {$\left[(1-\alpha)^{-2}-1\right] / 2$} \\
R2 & Contracting area & $2(1-\alpha)^{1 / 2}$ & $1-(1-\alpha)^{1 / 2}$ \\
R3 & Contracting & $3(1-\alpha)^{2 / 3}$ & $1-(1-\alpha)^{1 / 3}$ \\
& volume & &
\end{tabular}




\begin{tabular}{|c|c|c|c|c|}
\hline \multirow[b]{2}{*}{ Sample } & \multicolumn{2}{|c|}{ First stage } & \multicolumn{2}{|c|}{ Second stage } \\
\hline & $\mathrm{T}_{\text {peak }}\left({ }^{\circ} \mathrm{C}\right)$ & $\begin{array}{c}\text { Temperature } \\
\text { range }\left({ }^{\circ} \mathrm{C}\right)\end{array}$ & $\mathrm{T}_{\text {peak }}\left({ }^{\circ} \mathrm{C}\right)$ & $\begin{array}{c}\text { Temperature } \\
\text { range }\left({ }^{\circ} \mathrm{C}\right)\end{array}$ \\
\hline Cellulose & 338 & $300-360$ & - & - \\
\hline Lignin & - & - & 548 & $450-600$ \\
\hline Almond shell & 298 & $250-390$ & 477 & $400-720$ \\
\hline Apple tree leaves & 311 & $220-350$ & 414 & $410-600$ \\
\hline Beetroot pellets & 342 & $210-380$ & 541 & $400-640$ \\
\hline Briquette & 343 & $260-400$ & 509 & $410-550$ \\
\hline Charcoal & - & - & 490 & $400-900$ \\
\hline Chestnut tree chips & 335 & $260-370$ & 473 & $400-520$ \\
\hline Cocoa bean husk & 312 & $225-350$ & 627 & $425-634$ \\
\hline Coffee bean husk & 319 & $220-360$ & 502 & $440-520$ \\
\hline Corncob & 289 & $250-340$ & 454 & $400-550$ \\
\hline Eucalyptus tree chips & 340 & $250-370$ & 486 & $420-520$ \\
\hline Extracted olive pomace & 328 & $230-360$ & 550 & $400-725$ \\
\hline Gorse & 339 & $250-390$ & 560 & $450-570$ \\
\hline Grape seed flour & 340 & $255-375$ & 546 & $400-775$ \\
\hline Miscanthus & 307 & $240-340$ & 550 & $450-550$ \\
\hline Olive stone & 340 & $260-360$ & 418 & $400-820$ \\
\hline Olive tree pruning & 342 & $250-375$ & 469 & $430-570$ \\
\hline Pepper plant & 311 & $220-374$ & 460 & $400-807$ \\
\hline Pine and pineapple leave pellets & 324 & $250-360$ & 422 & $400-740$ \\
\hline Pine kernel shell & 249 & $270-370$ & 515 & $400-820$ \\
\hline Pineapple leaf & 344 & $250-380$ & 496 & $420-570$ \\
\hline Rice husk & 334 & $260-360$ & 450 & $400-540$ \\
\hline Sainfoin & 301 & $230-330$ & 456 & $390-522$ \\
\hline Scrubland pruning & 334 & $260-370$ & 538 & $400-760$ \\
\hline Thistle & 345 & $240-400$ & 473 & $420-550$ \\
\hline Vine shoot & 318 & $250-380$ & 468 & $420-500$ \\
\hline Wheat straw & 312 & $260-360$ & 543 & $420-650$ \\
\hline Wheat straw pellets & 300 & $230-365$ & 458 & $400-528$ \\
\hline
\end{tabular}


Table 3. Kinetic parameters obtained by means of Coats-Redfern method.

\begin{tabular}{|c|c|c|c|c|c|c|}
\hline \multirow[b]{2}{*}{ Sample } & \multicolumn{3}{|c|}{ Stage 1} & \multicolumn{3}{|c|}{ Stage 2} \\
\hline & $\mathbf{k}_{\mathbf{o}}$ & $\mathrm{Ea} \mathrm{(J/mol)}$ & $\mathbf{R}^{2}$ & $\mathbf{k}_{\mathbf{o}}$ & $\mathrm{Ea} \mathrm{(J/mol)}$ & $\mathbf{R}^{2}$ \\
\hline Cellulose & $9.47 E+17$ & $2.12 \mathrm{E}+05$ & 0.997 & - & - & - \\
\hline Lignin & - & - & - & $6.87 E+03$ & $6.95 E+04$ & 0.98 \\
\hline Almond shell & 2.07E+03 & 4.82E+04 & 0.994 & $1.00 E+00$ & $1.71 E+04$ & 0.94 \\
\hline Apple tree leaves & $3.54 \mathrm{E}+01$ & $2.94 \mathrm{E}+04$ & 0.997 & $2.65 E+00$ & $2.06 \mathrm{E}+04$ & 0.996 \\
\hline Beetroot pellets & $5.36 \mathrm{E}+00$ & $2.16 E+04$ & 0.998 & $3.99 E+00$ & $2.32 E+04$ & 0.98 \\
\hline Briquette & 4.65E+02 & 4.28E+04 & 0.997 & $2.24 \mathrm{E}+03$ & $5.55 E+04$ & 0.96 \\
\hline Charcoal & - & - & - & 9.17E-01 & $2.29 E+04$ & 0.98 \\
\hline Chestnut tree chips & $1.35 E+03$ & $4.66 \mathrm{E}+04$ & 0.998 & $2.83 E+03$ & 5.38E+04 & 0.98 \\
\hline Cocoa bean husk & $2.86 \mathrm{E}+01$ & $2.90 E+04$ & 0.995 & $6.28 E-01$ & $1.51 E+04$ & 0.99 \\
\hline Coffee bean husk & $1.06 \mathrm{E}+02$ & $3.46 \mathrm{E}+04$ & 0.998 & $7.10 \mathrm{E}+03$ & $6.25 E+04$ & 0.96 \\
\hline Corncob & $1.65 \mathrm{E}+07$ & 8.69E+04 & 0.994 & $3.20 E+00$ & $1.95 \mathrm{E}+04$ & 0.93 \\
\hline Eucalyptus tree chips & 4.60E+02 & 4.18E+04 & 0.9995 & 1.03E+04 & $6.30 \mathrm{E}+04$ & 0.98 \\
\hline Extracted olive pomace & $5.96 \mathrm{E}+01$ & 3.23E+04 & 0.993 & 5.08E-01 & $1.46 \mathrm{E}+04$ & 0.92 \\
\hline Gorse & $3.07 E+01$ & $3.07 E+04$ & 0.997 & $3.31 E+02$ & $4.71 E+04$ & 0.95 \\
\hline Grape seed flour & $8.85 E+00$ & $2.56 \mathrm{E}+04$ & 0.995 & $3.09 E+02$ & $5.70 \mathrm{E}+04$ & 0.96 \\
\hline Miscanthus & $2.56 \mathrm{E}+02$ & $3.79 E+04$ & 0.996 & $6.76 \mathrm{E}+02$ & $5.09 E+04$ & 0.97 \\
\hline Olive stone & 1.37E+03 & 4.63E+04 & 0.98 & $7.33 E+01$ & $4.76 \mathrm{E}+04$ & 0.91 \\
\hline Olive tree pruning & 1.48E+02 & $3.64 E+04$ & 0.9991 & $2.26 \mathrm{E}+00$ & $1.92 E+04$ & 0.92 \\
\hline Pepper plant & $4.58 \mathrm{E}+00$ & $2.14 \mathrm{E}+04$ & 0.9993 & $7.02 E+01$ & 4.73E+04 & 0.95 \\
\hline Pine and pineapple leave pellets & $1.05 E+03$ & $4.51 E+04$ & 0.994 & 1.09E-01 & 7.35E+03 & 0.97 \\
\hline Pine kernel shell & $2.84 \mathrm{E}+02$ & $4.05 E+04$ & 0.996 & $7.91 \mathrm{E}+01$ & 4.81E+04 & 0.97 \\
\hline Pineapple leaf & $1.31 \mathrm{E}+02$ & $3.69 E+04$ & 0.997 & $5.33 E+02$ & 4.92E+04 & 0.95 \\
\hline Rice husk & $7.31 \mathrm{E}+03$ & $5.39 E+04$ & 0.9991 & 4.13E+01 & $3.28 E+04$ & 0.92 \\
\hline Sainfoin & 1.64E+02 & $3.49 E+04$ & 0.996 & 1.88E+02 & $4.09 E+04$ & 0.995 \\
\hline Scrubland pruning & $2.26 \mathrm{E}+01$ & $2.90 E+04$ & 0.995 & $2.86 \mathrm{E}+00$ & $2.09 E+04$ & 0.92 \\
\hline Sorghum & 2.93E+03 & 4.99E+04 & 0.998 & $2.01 E+00$ & $1.81 \mathrm{E}+04$ & 0.98 \\
\hline Thistle & $9.64 \mathrm{E}+01$ & $3.46 E+04$ & 0.998 & $5.61 \mathrm{E}+01$ & $3.50 E+04$ & 0.99 \\
\hline Vine shoot & $5.12 \mathrm{E}+03$ & $5.16 \mathrm{E}+04$ & 0.998 & $8.68 \mathrm{E}+02$ & $4.82 E+04$ & 0.96 \\
\hline Wheat straw & $1.93 E+06$ & $7.75 E+04$ & 0.96 & $4.13 E+00$ & $2.34 \mathrm{E}+04$ & 0.92 \\
\hline Wheat straw pellets & $1.35 E+04$ & $5.46 \mathrm{E}+04$ & 0.995 & $1.51 \mathrm{E}+01$ & $2.75 \mathrm{E}+04$ & 0.96 \\
\hline
\end{tabular}


Table 4. Kinetic parameters obtained by numerical solution.

\begin{tabular}{|c|c|c|c|c|c|c|}
\hline \multirow{2}{*}{ Sample } & \multicolumn{3}{|c|}{ Stage 1} & \multicolumn{3}{|c|}{ Stage 2} \\
\hline & $\mathbf{k}_{\mathrm{o}}$ & Ea & $\mathbf{R}^{2}$ & $\mathbf{k}_{\mathrm{o}}$ & $\mathrm{Ea}$ & $\mathbf{R}^{2}$ \\
\hline Cellulose & $3.24 \mathrm{E}+10$ & $1.26 \mathrm{E}+05$ & 0.997 & - & - & - \\
\hline Lignin & & & & $4.49 \mathrm{E}+05$ & $9.73 E+04$ & 0.99993 \\
\hline Almond shell & $2.97 \mathrm{E}+02$ & $3.83 E+04$ & 0.9997 & $7.11 \mathrm{E}+01$ & $4.36 \mathrm{E}+04$ & 0.999996 \\
\hline Apple tree leaves & $1.29 \mathrm{E}+02$ & $3.42 \mathrm{E}+04$ & 0.9998 & $2.57 \mathrm{E}+01$ & $3.23 E+04$ & 0.999998 \\
\hline Beetroot pellets & $3.26 \mathrm{E}+00$ & $1.75 E+04$ & 0.999996 & $1.26 \mathrm{E}+03$ & $6.04 \mathrm{E}+04$ & 0.9999995 \\
\hline Briquette & $1.98 \mathrm{E}+04$ & $5.98 \mathrm{E}+04$ & 0.99996 & $3.90 \mathrm{E}+09$ & $1.48 \mathrm{E}+05$ & 0.9999997 \\
\hline Charcoal & & & & $1.09 \mathrm{E}+00$ & $2.10 \mathrm{E}+04$ & 0.9996 \\
\hline Chestnut tree chips & $1.76 \mathrm{E}+05$ & $6.88 \mathrm{E}+04$ & 0.9998 & $3.01 E+08$ & $1.24 \mathrm{E}+05$ & 0.99995 \\
\hline Cocoa bean husk & $2.48 \mathrm{E}+02$ & $3.77 E+04$ & 0.9998 & $9.87 \mathrm{E}+00$ & $2.91 E+04$ & 0.999997 \\
\hline Coffee bean husk & $9.03 \mathrm{E}+02$ & $4.35 E+04$ & 0.999996 & $4.70 \mathrm{E}+10$ & $1.62 \mathrm{E}+05$ & 0.999997 \\
\hline Corncob & $3.99 \mathrm{E}+07$ & $9.06 \mathrm{E}+04$ & 0.998 & $1.30 \mathrm{E}+03$ & $5.29 E+04$ & 0.999996 \\
\hline Eucalyptus tree chips & $2.02 E+03$ & $4.79 E+04$ & 0.99995 & $3.69 E+11$ & $1.72 E+05$ & 0.9999997 \\
\hline Extracted olive pomace & $2.04 \mathrm{E}+02$ & $3.69 \mathrm{E}+04$ & 0.9994 & $4.11 \mathrm{E}+01$ & $4.11 \mathrm{E}+04$ & 0.99998 \\
\hline Gorse & $1.28 \mathrm{E}+03$ & $4.72 E+04$ & 0.999995 & $3.64 \mathrm{E}+08$ & $1.38 \mathrm{E}+05$ & 0.999997 \\
\hline Grape seed flour & $1.19 \mathrm{E}+02$ & $3.64 \mathrm{E}+04$ & 0.99991 & $5.80 \mathrm{E}+00$ & $2.84 \mathrm{E}+04$ & 0.99997 \\
\hline Miscanthus & $3.11 \mathrm{E}+03$ & $4.87 E+04$ & 0.9998 & $4.30 \mathrm{E}+07$ & $1.22 \mathrm{E}+05$ & 0.999998 \\
\hline Olive stone & $2.00 \mathrm{E}+02$ & $3.63 E+04$ & 0.9995 & $1.80 \mathrm{E}+00$ & $2.09 E+04$ & 0.99998 \\
\hline Olive tree pruning & $2.31 \mathrm{E}+03$ & $4.85 E+04$ & 0.99995 & $2.15 E+03$ & $5.89 E+04$ & 0.999991 \\
\hline Pepper plant & $2.10 \mathrm{E}+01$ & $2.68 \mathrm{E}+04$ & 0.999993 & $3.58 \mathrm{E}+11$ & $2.37 E+05$ & 0.999999994 \\
\hline Pine and pineapple leave pellets & $7.78 \mathrm{E}+04$ & $6.46 \mathrm{E}+04$ & 0.99995 & $1.20 \mathrm{E}+00$ & $1.62 \mathrm{E}+04$ & 0.999994 \\
\hline Pine kernel shell & 7.07E+03 & $5.51 \mathrm{E}+04$ & 0.99997 & $2.03 E+02$ & $5.66 \mathrm{E}+04$ & 0.999998 \\
\hline Pineapple leaf & $3.53 E+03$ & $5.15 E+04$ & 0.999995 & $3.13 E+04$ & $7.61 \mathrm{E}+04$ & 0.9999991 \\
\hline Rice husk & $1.57 \mathrm{E}+04$ & $5.69 \mathrm{E}+04$ & 0.99991 & $1.85 \mathrm{E}+04$ & $6.95 \mathrm{E}+04$ & 0.99997 \\
\hline Sainfoin & $2.00 \mathrm{E}+03$ & $4.53 \mathrm{E}+04$ & 0.9998 & $2.11 \mathrm{E}+04$ & $6.88 \mathrm{E}+04$ & 0.999994 \\
\hline Scrubland pruning & $4.09 \mathrm{E}+03$ & $5.24 \mathrm{E}+04$ & 0.99998 & $3.57 \mathrm{E}+03$ & $6.21 \mathrm{E}+04$ & 0.99998 \\
\hline Sorghum & $1.09 \mathrm{E}+04$ & $5.54 \mathrm{E}+04$ & 0.9997 & $1.79 \mathrm{E}+01$ & $2.81 \mathrm{E}+04$ & 0.999980 \\
\hline Thistle & $3.65 \mathrm{E}+03$ & $5.08 \mathrm{E}+04$ & 0.999991 & $2.35 \mathrm{E}+05$ & $8.64 \mathrm{E}+04$ & 0.999998 \\
\hline Vine shoot & $3.24 \mathrm{E}+04$ & $5.97 \mathrm{E}+04$ & 0.99992 & $3.31 \mathrm{E}+10$ & $1.54 \mathrm{E}+05$ & 0.9999992 \\
\hline Wheat straw & $2.59 \mathrm{E}+13$ & $1.55 \mathrm{E}+05$ & 0.9998 & $1.25 \mathrm{E}+01$ & $3.06 \mathrm{E}+04$ & 0.99997 \\
\hline Wheat straw pellets & $6.25 \mathrm{E}+06$ & $8.21 \mathrm{E}+04$ & 0.99992 & $3.90 \mathrm{E}+04$ & $1.54 \mathrm{E}+05$ & 0.999998 \\
\hline
\end{tabular}


328 Table 5. Gompertz model parameters of the biomass samples analysed.

\begin{tabular}{lccc}
\hline \multicolumn{1}{c}{ Sample } & $\mathbf{A}$ & $\boldsymbol{\mu}\left(\mathbf{K}^{-1}\right)$ & $\mathbf{T}_{\mathbf{c}}(\mathbf{K})$ \\
\hline Almond shell & 0.999 & 0.016 & 597.9 \\
Apple tree leaves & 1.292 & 0.074 & 591.3 \\
Beetroot pellets & 0.852 & 0.029 & 638.8 \\
Briquette & 0.957 & 0.031 & 637.8 \\
Charcoal & - & - & - \\
Chestnut tree chips & 1.000 & 0.064 & 633.7 \\
Cocoa bean husk & 1.000 & 0.145 & 594.5 \\
Coffee bean husk & 0.879 & 0.032 & 606.9 \\
Corncob & 1.014 & 0.028 & 573.2 \\
Eucalyptus tree chips & 0.949 & 0.019 & 621.2 \\
Extracted olive pomace & 0.996 & 0.017 & 589.7 \\
Gorse & 0.976 & 0.012 & 603.6 \\
Grape seed flour & 1.372 & 0.018 & 603.2 \\
Miscanthus & 1.000 & 0.017 & 583.0 \\
Olive stone & 1.011 & 0.035 & 616.0 \\
Olive tree pruning & 1.016 & 0.023 & 605.2 \\
Pepper plant & 0.677 & 0.050 & 593.6 \\
Pine and pineapple leave pellets & 1.251 & 0.029 & 595.8 \\
Pine kernel shell & 1.000 & 0.011 & 595.2 \\
Pineapple leaf & 0.988 & 0.021 & 613.0 \\
Rice husk & 1.002 & 0.029 & 606.9 \\
Sainfoin & 1.509 & 0.056 & 586.2 \\
Scrubland pruning & 1.031 & 0.019 & 600.4 \\
Sorghum & 1.000 & 0.052 & 600.5 \\
Thistle & 1.944 & 0.016 & 612.1 \\
Vine shoot & 0.991 & 0.018 & 593.9 \\
Wheat straw & 1.000 & 0.068 & 588.7 \\
Wheat straw pellets & 0.976 & 0.023 & 570.8 \\
\hline & & & \\
\hline & & & \\
& & &
\end{tabular}




\section{FIGURE CAPTIONS}

331 Fig. 1. DTG curves of the combustion process ( $\beta=15 \mathrm{~K} / \mathrm{min})$ of biomass

332 samples analysed. (PPLP in b is the pine and pineapple leave pellet sample).

333 Fig 2. Matches between DTG and Ea values in FWO and KAS methods.

334 Fig. 3a. Simulations for CR method; 1. Almond shell; 2. Apple tree leaves; 3.

335 Beetroot pellets; 4. Briquette; 5. Charcoal; 6. Chestnut tree chips; 7. Cocoa

336 bean husk; 8. Coffee bean husk; 9. Corncob; 10. Eucalyptus tree chips; 11.

337 Extracted olive pomace; 12. Gorse; 13. Grape seed flour; 14. Miscanthus; 15.

338 Olive stone; 16 . Olive tree pruning.

339 Fig. 3b. Simulations for CR method; 17. Pepper plant; 18. Pine and pineapple

340 leave pellets; 19. Pine kernel shell; 20. Pineapple leaf; 21. Rice husk; 22.

341 Sainfoin; 23. Scrubland pruning; 24. Sorghum; 25. Thistle; 26. Vine shoot; 27.

342 Wheat straw; 28. Wheat straw pellets. 

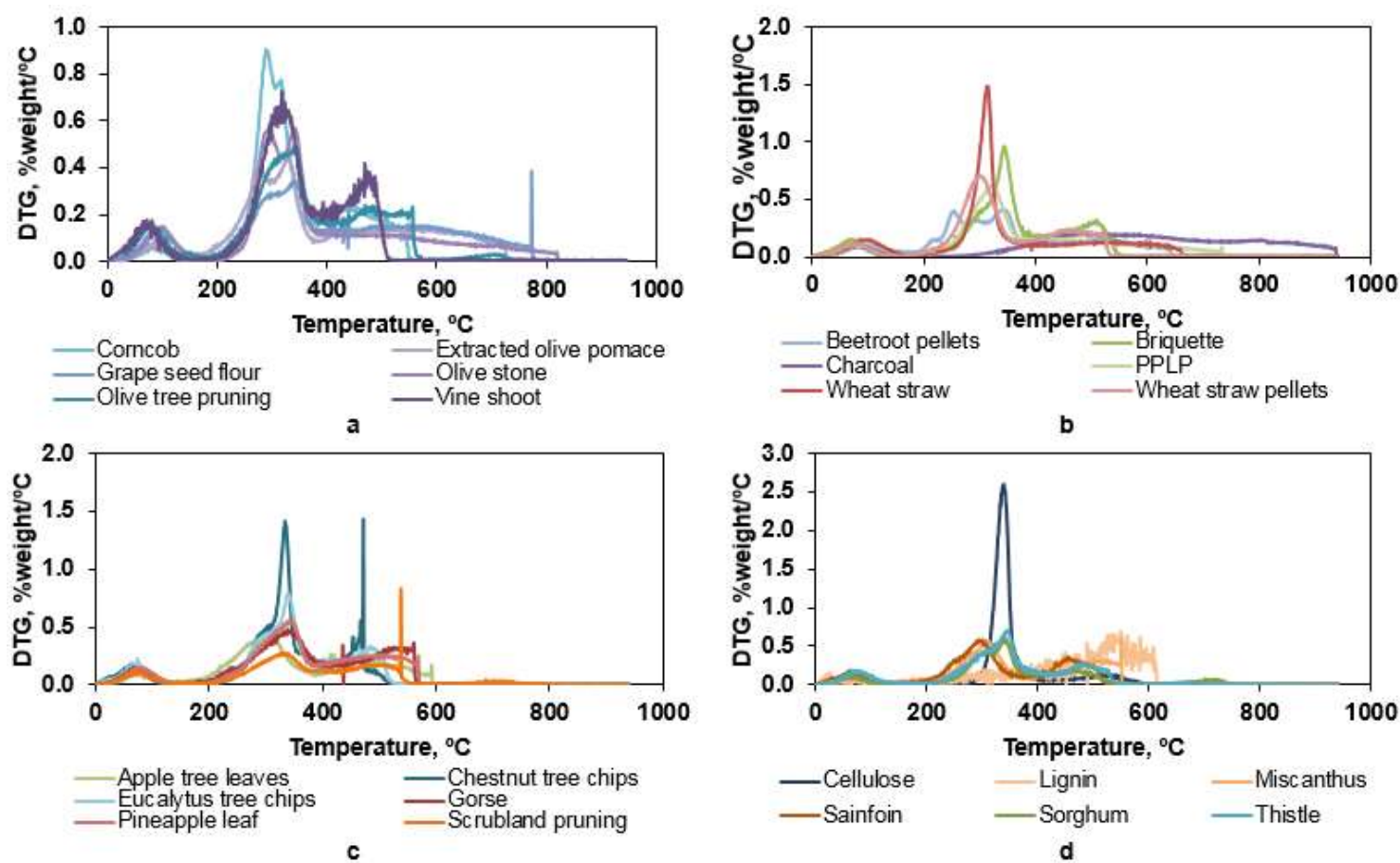

d
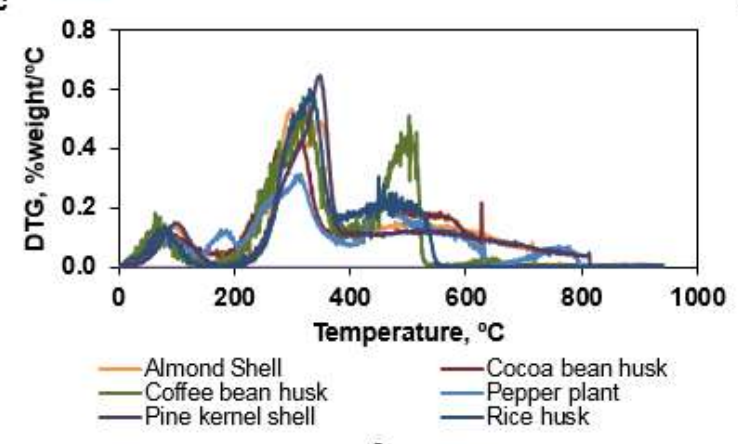

Fig. 1. DTG curves of the combustion process ( $\beta=15 \mathrm{~K} / \mathrm{min}$ ) of biomass samples analysed. (PPLP in $b$ is the pine and pineapple leave pellet sample) 


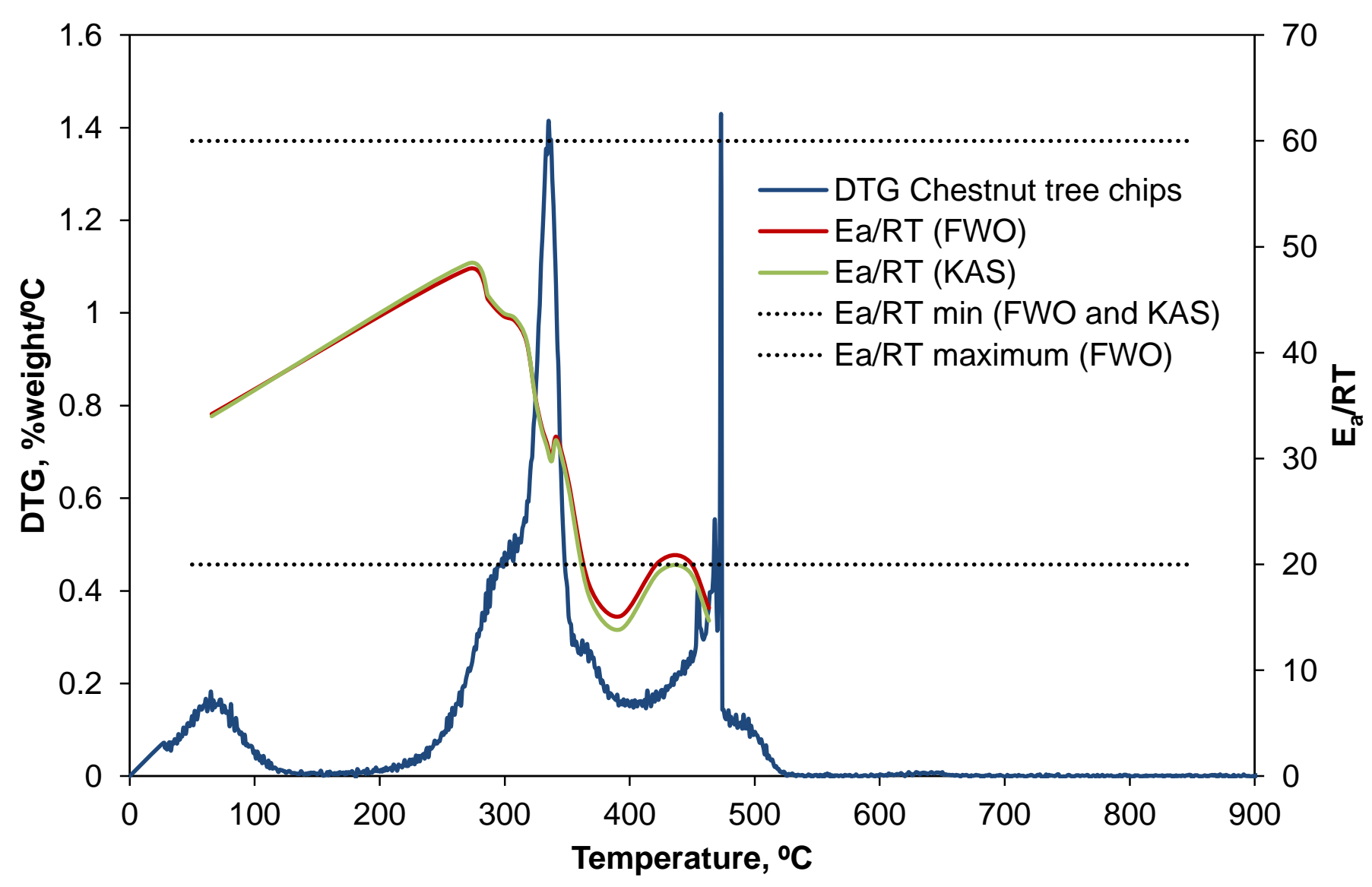

347 Fig 2. Matches between DTG and Ea values in FWO and KAS methods 

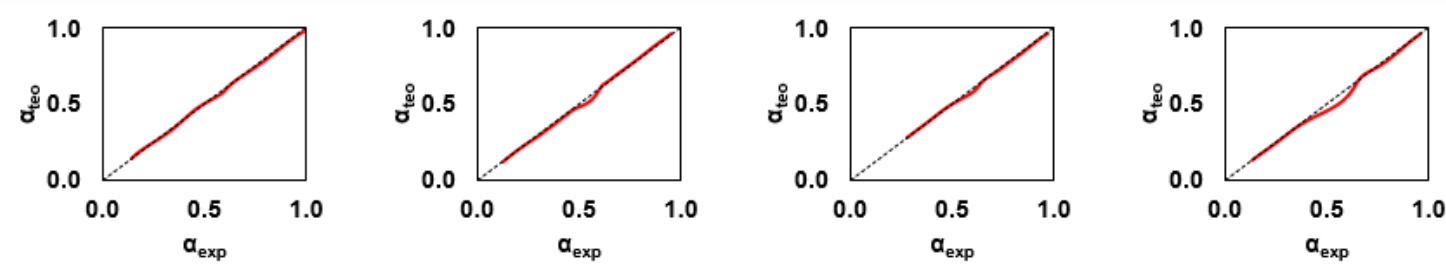

2
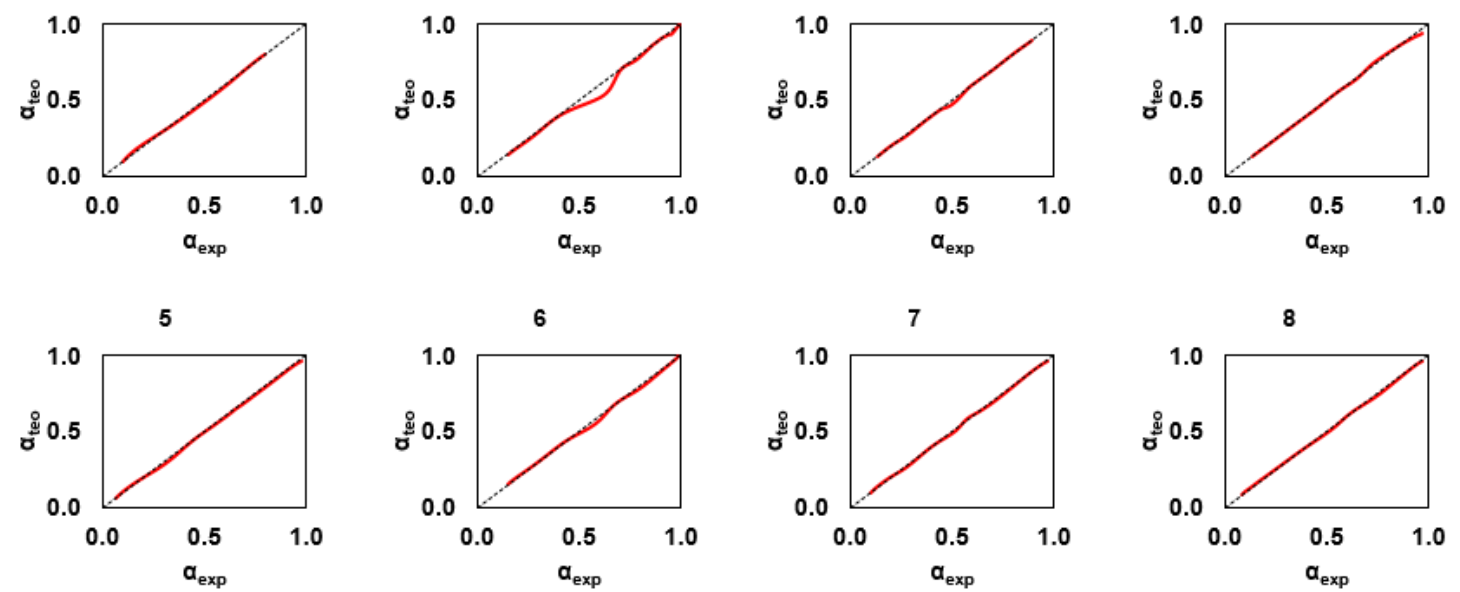

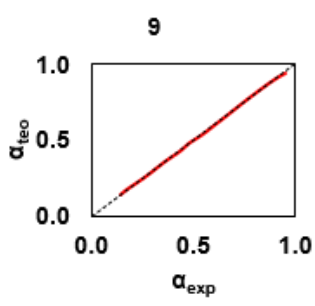

13

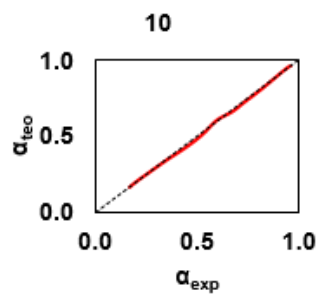

14

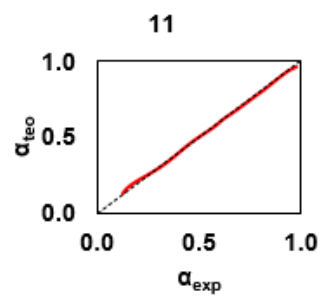

15

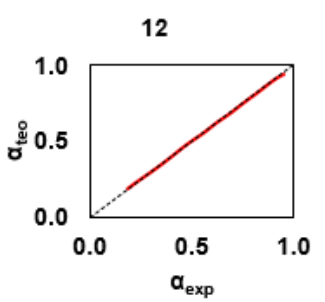

16

349 Fig. 3a. Simulations for CR method; 1. Almond shell; 2. Apple tree leaves; 3.

350 Beetroot pellets; 4. Briquette; 5. Charcoal; 6. Chestnut tree chips; 7. Cocoa

351 bean husk; 8. Coffee bean husk; 9. Corncob; 10. Eucalyptus tree chips; 11.

352 Extracted olive pomace; 12. Gorse; 13. Grape seed flour; 14. Miscanthus; 15.

353 Olive stone; 16 . Olive tree pruning. 

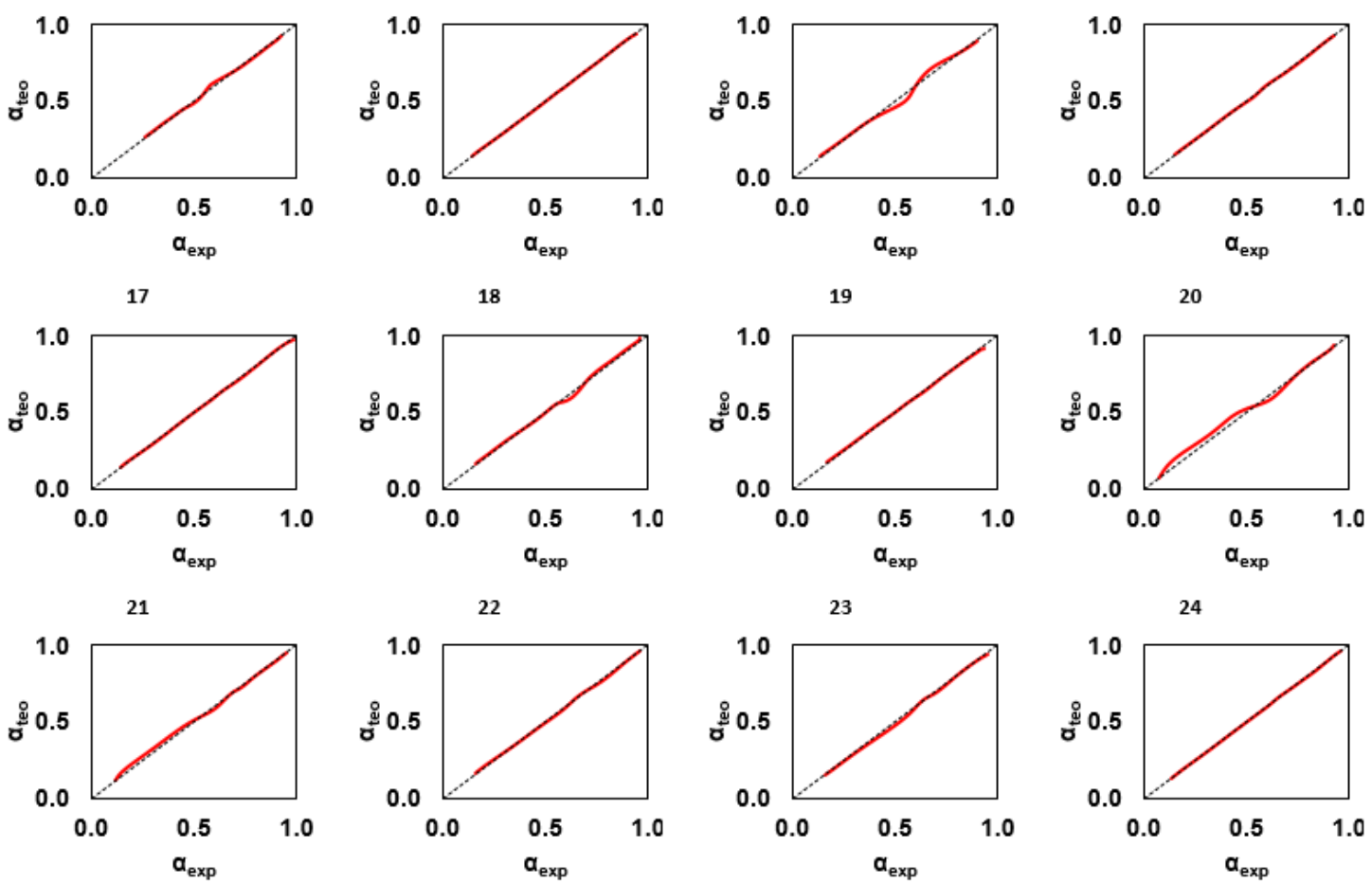

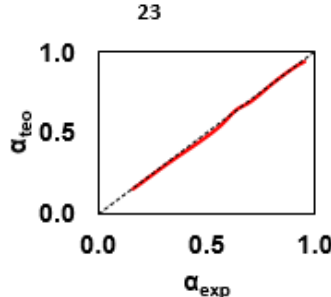

27

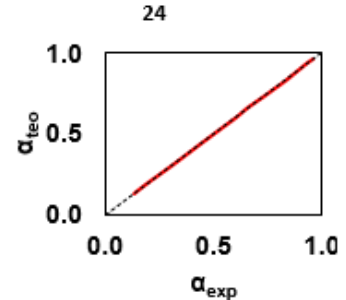

28

355 Fig. 3b. Simulations for CR method; 17. Pepper plant; 18. Pine and pineapple 356 leave pellets; 19. Pine kernel shell; 20. Pineapple leaf; 21. Rice husk; 22.

357 Sainfoin; 23. Scrubland pruning; 24. Sorghum; 25. Thistle; 26. Vine shoot; 27. 358 Wheat straw; 28. Wheat straw pellets. 